\title{
Anastatica Hierochuntica L. Used As an Alternative of Conjugated Estrogen (Premarin) in Rabbit Females \\ Bushra H.Ali ${ }^{1}$ Rajaa K.Baker ${ }^{1}$ Taghreed U.Mohammd ${ }^{1}$ \\ Huda A. Hassn ${ }^{1}$ \\ ${ }^{1}$ Chemistry department, Colloge of Education for Pure Science - Ibn- \\ Al-Haitham, Baghdad University, Baghdad, Iraq \\ tagreedaloom@gmail.com; \\ dr.bushra750@yahoo.com;Rajaaka1@gmail.com;hudallgh@yahoo.com
}

\begin{abstract}
:
There are risks and benefits with all medicines and estrogen replacement is no exception. In fact, estrogen replacement is one of the most controversial topics in Endocrinology. Anastatica hierochuntica L. is a popular treatment for the management of female reproductive disorders. The present research highlights the effect of aqueous extract of plant against conjugated estrogen(Premarin) in rabbits. Femal oryciolagus cuniculus rabbits were divided into four groups: the 1 st group, rabbits were orally administered (using a feeding solution )with daily dose $(5 \mathrm{~mL}$ distilled water)for two months, the $2^{\text {nd }}$ group, the rabbits were treated with conjugated estrogen $(50 \mu \mathrm{g} / \mathrm{kg} \mathrm{b.w}$, body weight $)$ for one month. The $3^{\text {rd }}$ group, the rabbits were treated with aqueose extract of plant $(100 \mathrm{mg} / \mathrm{mL})$ for one month and group $4^{\text {th }}$ the rabbits were treated with aqueous extract of plant $(100 \mathrm{mg} / \mathrm{mL})$ for two months . The level of estrogen evaluated in blood. The findings of the study indicated that the administration of conjugated estrogen $(50 \mu \mathrm{g} / \mathrm{kg} \mathrm{b}$. w) induced a significant increase in estrogen. The result suggests that aqueous extract of Anastatica hierochuntica L. may increased leve of estrogen.
\end{abstract}

Keyword: Anastatica hierochuntica L., Estrogen, conjugated estrogen( Premarin).

\section{Summary}

Anastatica hierochuntica is believed to be very useful in Arab countries for treating various health disorders. The aqueous extract of Anastatica hierochuntica was investigated for it is estrogen in Rabbit females.

\section{Council for Innovative Research}

Peer Review Research Publishing System

\section{Journal: Journal of Advances in Chemistry}

Vol. 9, No. 1

editorjaconline@gmail.com

www.jac.cirworld.com, member.cirworld.com 


\section{Introduction}

Anastatica hierochuntica L. belongs to the family Brassicaceae and the only member of the genus Anastatica. This desert annual plant, also known as 'the true rose of Jericho' is a resurrection plant found in arid areas in the Negev and Sahara desert . It is a small grey herb that rarely grows above $15 \mathrm{~cm}$ high. The plant is mostly a few centimeters high with minute, white, sessile flowers and oblong dentate leaves [1]. After the rainy season, the A. hierochuntica L. dies and dries up, curling its stems inward into a tight woody ball $4-10 \mathrm{~cm}$ in diameter. The seeds of the plant are very hard and can be dormant for years. When soaked in water, the branches would spread out and a fraction of the seeds are dispersed [2] The dry lignified stem branches are curled around the enclosed fruits and uncurl hygrochastically when wet.

Anastatica hierochuntica L. is among the common medicinal plants widely used in Hijaz, Najd and Al- Rub'Al Kali [3]. The plant is still popularly used as herbal remedy [4] for difficult labor, uterine hemorrhage, management of female reproductive disorders including corups luteum insufficiency, premenstrual syndrome (PMS), menopausal symptoms, insufficient milk production and to facilitates the expulsion of dead fetuses [5].

Estrogens are a group of compounds named for their importance in both menstrual and estrous reproductive cycles. They are the primary female sex hormones. Natural estrogens are steroid hormones, while some synthetic ones are nonsteroidal [6].

Estrogens are synthesized in all vertebrates [7] as well as some insects [8]. Their presence in both vertebrates and insects suggests that estrogenic sex hormones have an ancient evolutionary history.

Estrogens are used as part of some oral contraceptive, in estrogen replacement therapy for postmenopausal women, and in hormone replacement therapy for trans women. Like all steroid hormones, estrogens readily diffuse across the cell membrane. Once inside the cell, they bind to and expression of many genes [9]. Additionally, estrogens have been shown to activate a G protein- coupled receptor, GRP30[10].

Premarin is the commercial name for a medication consisting primarily of conjugated estrogens. The major forms of estrogen in Premarin are estrone (>50\%), equilin (15-25\%) and equilenin. The estrogens in Premarin are often called "conjugated equine estrogens" (CEE) because the estrogen molecules are generally present with hydrophilic side-groups attached such as sulfate[11]. Thus, estrone sulfate is actually the major active constituent in Premarin. Estrone sufate is easily absorbed into the blood after Premarin pills are taken by women. Estrone sulfate is converted to estradiol , an active estrogen normally found in women. It is not clear if estrogen such as equilin that are foreign to the human body have effects in women that are significantly different from the estrogens like estradiol that are normally made in the human body[12].

Premarin is a form of hormone replacement therapy. Premarin pills are used most commonly in post menopausal women who have had a hysterectomy to treat hot flashes, and burning, itching, and dryness of the vagina and surrounding areas[13]. It can also be used in conjunction with a progestin pill in women who have not had a hysterectomy. For women already taking the drug it can be used to treat osteoporosis, although it is not recommended solely for this infection, vaginal spotting or bleeding, painful menses, and cramping of the legs[14].

The aim of this study was to evaluate the effect of the aqueous extract of Anastatica hierochuntica L.on estrogen levels in rabbit females induced by conjugated estrogen ( Premarin).

\section{Materials and methods:}

\section{Plant material} Iraq.

The plant of healthy Anastatica hierochuntica L. under investigation were purchased from a local market at Baghdad,

\section{Preparation of Anastatica hierochuntica L. extract:}

Samples of whole dried Anastatica hierochuntica L. were brought from Iraqi market in Baghdad, then aerial parts of the plant were isolated and kept in airtight glass containers till the time of the experiment. Then the dried plant was ground to fine powder. $25 \mathrm{gm}$ of the powder, mixed with $250 \mathrm{~mL}$ of distilled water and were incubated for $3 \mathrm{hrs}$ at $(60) \mathrm{C}^{\circ}$ Suspension was then filtered. Water extracts were prepared daily just before administration orally to the experimental animals in a dose of $(50 \mu /(1.5-2) \mathrm{kg}$ body weight $)$.

\section{CHEMICAL AND DRUG}

The conjugated estrogen was purchased from Al-Sophee Pharma, Baghdad, Iraq. The level of estrogen was assayed by using ELSA (Human Germany), supplied from Monobind Inc.

\section{Animals:}

Female oryciolagus cuniculus rabbits $(1.5-2 \mathrm{~kg})$ were purchased from the Laboratories of city of medicine, (Baghdad, Iraq) were used in the experiments. Prior to the experiments, rabbits were fed with multivitamin, vegetables, and wheat. The animals were kept on standard laboratory dite, and under the same hygienic conditions. 9 animals were used for each group of study.

Group I: Normal control rabbits received with standard fed and water for 2 months. 
Group II: Rabbits were orally fed $50 \mu \mathrm{g} / \mathrm{b} . \mathrm{w}$ of esrtrogen once daily for one month.

Group III: Rabbits were treated with Anastatica hierochuntica L. + estrogen (100mg/mL) for a period of one month.

Group IV: Rabbits were treated with just Anastatica hierochuntica L. (100mg/mL) for two months

The blood samples were collected from the rabbit heart using heparinized capillary tube. Serum was separated by centrifugation at $2000 \mathrm{rpm}$ for $10 \mathrm{~min}$.

Descriptive analysis was used to show the mean \pm standard deviation of variables. The significance of difference between mean values was estimated by Student $T$ - test. The probability $p<0.05=$ significant.

\section{Results and discussion:}

Results are given in figuer (1). In the present study, in Conjugated Estrogen group (G2) the mean value of estrogen was found to be $24.04 \pm 0.29 \mathrm{pg} / \mathrm{mL}$,. In treatment group (G3) the estrogen was $42.61 \pm 0.55 \mathrm{pg} / \mathrm{mL}$. The results show that mean estrogen levels in group (G2) are significantly higher as compared to control rabbits group. The treatment group (G3) and (G4) with plant extract showed the significant highest of estrogen level.

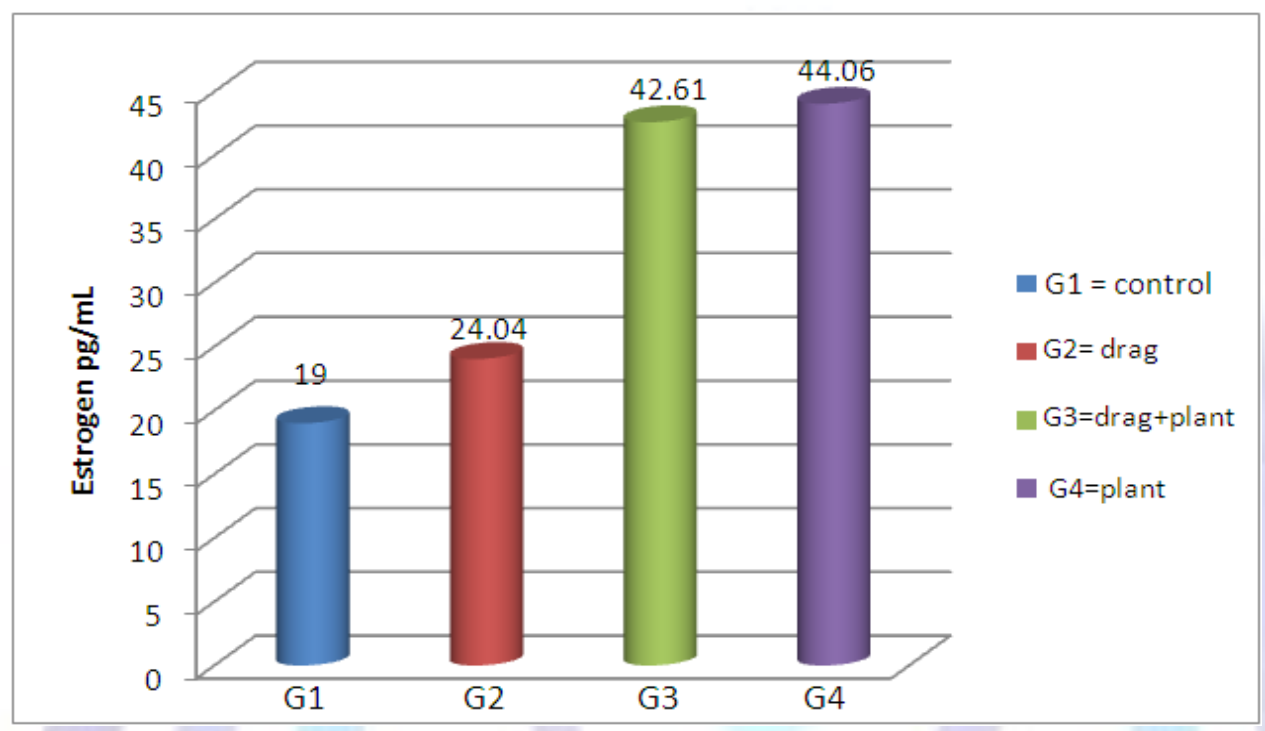

Fig(1): Mean value of blood estrogen levels in rabbit females

Estrogen is considered to play a significant role in women's mental health. Sudden estrogen withdrawal, fluctuating estrogen, and period of sustained estrogen low levels correlate with significant mood lowering. Clinical recovery from postpartum, perimenopause, and postmenopause depression has been shown to be effective after levels of estrogen were stabilized and/or restored[15,16]

Permarin tablets contain conjugated estrogen, a mixture of estrogen obtained from natural source. Permarin is used to treat symptoms of menopause such as hot flashes, and vaginal dryness, burning, and irritation. Continued use of estrogen can increase the risk of endometrial carcinoma, gallbladder disease, and thrombolic disorders. Because of the danger of damage to the fetus, all female sex hormones are contraindication during pregnancy[17].

In the present study, the prior administration of aqueous extract of plant was significantly induced elevation in the levels of estrogen may be attributed to the physiological role of bioactive compounds present in plant has attracted more attention over the last decade, especially the phytoestrogens. Traditional medicines have been used in the treatment of menopausal symptoms for several thousands of years in Asian countries, but many mysteries remain about the relationship between the active component and their function owing to the complexity of the mixtures[18].

In addition to being a rich source of important minerals, all parts of Anastatica hierochuntica L., especially the leaf buds, were found to be rich in total phenolic content, and to have antioxidant and free radical- scavenging activities. Recently, the phenolic content and the antioxidant and free radical- scavenging properties of natural products have generated tremendous research interest owing to their related anticancer and antimutagenic properties, as well as their protective effect against cardiovascular disease and their ability to confer decreased risk of certain chronic disease, as reported by Weichselbaum and Buttirss (2010) and Saura -Calixto(2011)[19,20].

Pharmacologic studies found that grass plants Anastatica hierochuntica L.contains flavonoids substance having estrogenic activity, but up now, the mechanism of this plant on the uterus contraction has not been clearly known[21] 


\section{Conclusion}

The results indicated that the most common side effect associated with conjugated estrogen (Premarin). Anastatica hierochuntica L. aqueous extract has increase the level of estrogen hormone. It has therapeutic action and may be has the same mechanism of estrogen, and has been suggested to be in treatment of several disease.

\section{REFRENCES}

1. Law KS, Soon LK, Syed Mohsin SSJ, Farid CG. 2009 . Ultrastructural Findings of Anastatica hierochuntica L. (Sanggul Fatimah) towards explaining its Medicinal Properties. Annals of Microscopy. 9: 50-56.

2. Hassan F, Shaaban J. 2005. Use of traditional /complimentary medicine among adult patients attending Family Medicine Clinical at Hospital Universty Sains Malaysia. International Medical Journal, 12:1-6.

3. Noura A, William M, Alan C. (2011) Tea prepared from Anastatica hierochuntica seeds contains a diversity of antioxidant flavonids, chlorogenic acids and phenolic compounds. Phytochemistry, $\underline{72}: 248-254$.

4. Ihsanullah D. (2012) Chemical properties of the medicinal herb Kaff maryam(Anastatica hierochuntica L.) and its relation to folk medicine use. African Journal of Microbiology Research, $\underline{6}(23)$ : 5048-5051.

5. Anita R. Sh, Anupam Sh. (2012) Anti- anxiety and CNS modulatory activities of Vitex aguns- castus Linn. Phytopharamacology, $\underline{3}(1): 29-37$.

6. Ryan KJ. 1982. Biochemistry of aromatase: significance to female reproductive physiology. Cancer Res. 42(8):3342s3344s.

7. Nadkarni S, Cooper D, Bracaleone V, Bena S, Perretti M. 2011. Activation of the annexin A1 pathway underlies the protective effect exerted by estrogen in polymorphonuclear leukocytes. Arterioscler. Thromb. Vase. Biol. 31(11): 2749-59.

8. Walter F. Boron, Emile L. Boulpaep. 2003. Medical Physiology : A cellular And Molecular Approach. Elsevier/ Saunders.1300. ISBN 1-4160-2328-3.

9. Nelson LR, Bulun SE. 2001. Estrogen production and action. J. Am. Acad. Dermatol. 45(3):S116-24.

10. Prossnitz ER, Arterburn JB, Sklar LA. 2007. GPR30: A G protein -coupled receptor for estrogen. Mol. Cell. Endocrinol.265-266: 138-42.

11. Ziel HK, Finkle WD. Increased risk of endometrial carcinoma among users of conjugated estrogen. New England Journal of Medcine. 293:1167-1170.

12. Brunner RL, et al. Women's Health Initiative Investigators2005. Effect of conjugated equine estrogen on healthrelated quality of life in postmenopausal women with hysterectomy: result from the Women's Health Initiative Randomized Clinical Trial. 165(17): 1976-1986.

13. Ray N. et al. 2003. The neuroprotective effect of estrogen on the aging brain. Experimental Gerontology. 38: 109117.

14. Asthana S, Baker L.D, Craft S, Stanczyk F.Z, Veith R.C, Raskind M.A, Plymate S.R. 2001. High-dose estradiol improves cognition for women with AD: results of a randomized study. Neurology 57: 605-612.

15. Douma SL, Husband C, O'Donnell ME, Barwin BN, Woodend AK.2005. Estrogen -related mood disorders: reproductive life cycle factors. Advances in Nursing Science .28(4):364-75.

16. Lasiuk GC, Hegadoren KM. 2007. The effect of estradiol on central serotonergic systems and its relationship to mood in women. Biol Res Nurs. 9(2):147-60.

17. McDonald TW et al. 1975. Exogenous estrogen and endometrial carcinoma: case-control and incidence study. American J Obstet Gynecol. 127: 572-580.

18. Zhang C.Z, Wang S.X, Zhang Y, Chen J.P, Liang X.M. 2005. In vitro estrogenic activities of Chinese medicinal plants traditionally used for the management of menopausal symptoms. Journal of Ethnopharmacology. 98:295300.

19. Weichselbaum E, Buttriss JL. 2010. Polyphenols in the diet. Nutr. Bull.35: 157-164.

20. Saura-Calixto F. 2011. Dietary fibre as a carrier of dietary antioxidants :an essential physiological function. J. Agric. Food Chem. 59:43-49.

21. Sharma P, Gujral HS. 2010. Antioxidant and polyphenol oxidase activityof germinated barley and its milling fraction. Food Chem. 120:6673-678. 